\title{
Development of a Material for Manufacturing a Mold for Plastic Injection
}

\author{
Alfredo González $z^{a}$ Ernesto Gustavo Maffia ${ }^{a *}$ \\ ${ }^{a}$ ProInTec I\&D, Departamento de Mecánica, Facultad de Ingeniería, Universidad Nacional de La Plata \\ (UNLP), 1900, BA, Argentina
}

Received: March 21, 2017; Accepted: July 12, 2017

\begin{abstract}
Injection molding is a process used to manufacture high volumes of plastic containers of complex geometric shapes. Although $\mathrm{CuBe}$ has always been used, there are currently some alternative alloys such as the CuNiSiCr alloy that has lower manufacturing cost and similar properties. The objective of this paper is to characterize, by techniques of microscopy, the process of fusion and thermo-mechanical treatments of the $\mathrm{CuNiSiCr}$ alloy. These results indicate that the forging process manages to break the grain boundary segregation without cracking the material. The hardness achieved after heat treatments is greater than $32 \mathrm{HRc}$ and conductivity reaches $27 \%$ IACS. These characteristics are similar to those of $\mathrm{CuBe}$ alloys.
\end{abstract}

Keywords: material for dies and injection molds, copper base alloy, microscopy characterization microstructures.

\section{Introduction}

At present, injection molding is a plastic processing technology widely used to manufacture components with complex geometric shapes and high production volumes. In order to achieve this goal, a mold of good mechanical and metallurgical qualities, with precise elaboration, and an acceptable duration is necessary.

Molding manufacture uses special steels because they meet the demanding working conditions imposed on the molds (high pressures, temperatures and abrasion, among others); however, they are not the only materials available today to manufacture these components.

In addition to steels, there is a wide range of materials, where it is possible to find casting materials, non-metallic materials and ceramics. As the main task of the injection mold is to receive and distribute the molten plastic material, with its subsequent cooling and ejection of the molded plastic part, it is advisable to take into account some considerations about the properties that the materials to be used must meet.

These materials should have:

- good machinability, being able to be forming and heat-treated;

- resistance to compression, temperature and abrasion;

- polishing ability;

- reduced deformation;

- good thermal conductivity;

- good chemical resistance;

- simple heat treatment.

Among the non-ferrous alloys available, copper base alloy $\mathrm{C} 17200(\mathrm{Cu}-2 \% \mathrm{Be})$ is one of the most used for its high strength and high thermal conductivity. It is widely

*e-mail: ernesto.maffia@ing.unlp.edu.ar used to manufacture plastic injection molds. The thermal conductivity of the copper base alloy C17200 is 3 to 4 times higher than that of any steel, and this property ensures a rapid and uniform removal of heat, minimizing the distortion of the part, mold deformation and poor reproduction of the details of the product. In many cases it can also significantly reduce cycle times.

Despite the excellent properties of $\mathrm{Cu}$-Be alloys, alloys without beryllium with hardness values above 30 Rockwell $\mathrm{C}$ and good electrical conductivity at the same time, are also necessary. (sometimes, it is also necessary to use alloys without beryllium with hardness values above 30 Rockwell $\mathrm{C}$ and good electrical conductivity at the same time).

A copper-nickel-silicon-chromium alloy ${ }^{1}$, forged or cast with high hardness is a possible alternative to this material. In general, the alloy consists of $8 \%$ to $12 \%$ nickel, 1 to $3.5 \%$ silicon, $0.5 \%$ to $2.0 \%$ chromium, and the remaining percentage of copper ${ }^{2}$. With this chemical composition, precise forming techniques and precipitation hardening treatment $t^{3,4}$ it is possible to achieve hardness above 30 Rockwell C, along with an electrical conductivity above $24 \%$ of pure copper.

This alloy may be used both as a molding die material in the extrusion of plastic parts or to form any part requiring a high elastic modulus as an essential property in service. An example of this latter application is found in the contact springs to transport electric current, in the case of computer equipment and / or electrical-electronic equipment.

In the case of being used as matrix material, an increase in hardness allows the material to withstand the high closure pressures of the mold, without distorting it. This hardness also makes it possible to resist the erosion of the molten plastic material, in particular when it contains fibrous material therein. In addition, as it is an alloy with excellent thermal 
diffusivity, it absorbs and dissipates the heat quickly, it reduces the time of cooling of the mold, thus reducing the cycle time in production. This alloy can be used to manufacture springs as it is easily conformable and its property extends by means of a simple heat treatment to provide the necessary elastic properties.

The properties of the $\mathrm{CuNiSiCr}$ alloy make it a suitable material for a wide variety of applications, especially in those materials that require a combination of high thermal conductivity, corrosion resistance and good surface finish. The objective of this development is to characterize, by techniques of microscopy, the process of fusion and thermomechanical treatments of the $\mathrm{CuNiSiCr}$ alloy to be used in plastic molds.

\section{Experimental}

The manufacture of the CuNiSiCr alloy starts from pure elements to avoid contamination of the material and to ensure that the conductivity is not affected by undesirable elements. The development of the melting is done by applying standard casting procedures, using a furnace heated with natural gas, with crucible of graphite and with the control of the atmosphere of the furnace.

The fusion sequence is as follows:

(A) copper and nickel are melted in the furnace at a maximum working rate, under commercial flux cover;

(B) when copper and nickel are in the liquid state, phosphorus (as copper-15\% phosphorus master alloy) is added to deoxidize the liquid mass;

(C) thereafter, silicon and chromium, as master alloys, are added according to required quantities to produce the desired composition; at this stage, it is important to ensure the conditions of exposure at the appropriate temperatures in order to achieve the dissolution of silicon and chromium;

(D) the melt is cast as soon as the solution of the silicon and the other alloys in the liquid mass is completed.

The ingots are obtained by cast casting gravity, which has a diameter of $150 \mathrm{~mm}$ and $600 \mathrm{~mm}$ height, using the "Durville" casting method. Once the ingot is obtained, it is analyzed chemically to determine the composition of the alloy: $11 \% \mathrm{Ni}, 1.5 \% \mathrm{Cr}$, and $2.5 \% \mathrm{Si}$. Subsequently, several specimens are forged at temperatures between 790 and 955 ${ }^{\circ} \mathrm{C}$, bringing the material to a suitable cross-section, not less than $12 \mathrm{~mm}$. All manufacturing stages are characterized by Optical Microscopy (M.O) techniques in an optical microscope (Leica) and Scanning Electron Microscopy (FEI QUANTA 200) with analytical capability (EDAX APOLO 40 dispersive energy analyzer).

The characterized samples are prepared with conventional metallographic techniques of roughing, polishing, and etching, using ferric chloride and potassium dichromate to reveal the microstructure, where necessary. Based on the samples obtained, a solubilization and hardening and a later aging are performed to evaluate hardness, grain size and second phase distribution. The conductivity of the aged samples is evaluated by means of a SIGMATEST conductivity meter and the hardness by the Rockwell method (C scale), with a UNIVERSAL FRANK durometer.

\section{Results}

\subsection{Characterization of the cast material}

In order to evaluate the resulting structures at each of the manufacturing stages (melting stage, homogenization stage and forging stage), microscopy (optics and electronics) is used for this industrial development of a copper base alloy for molds.

Initial observations are made on samples extracted from the ingot in "cast" condition. These samples are mirror-polished and when observed under an electronic microscope they reveal a highly segregated microstructure with a significant secondphase volume fraction in grain border, Figure 1. Obviously, this is an objectionable structure to perform any subsequent shaping and it has to be corrected, either by treatments of homogenates or by forming at high temperatures.

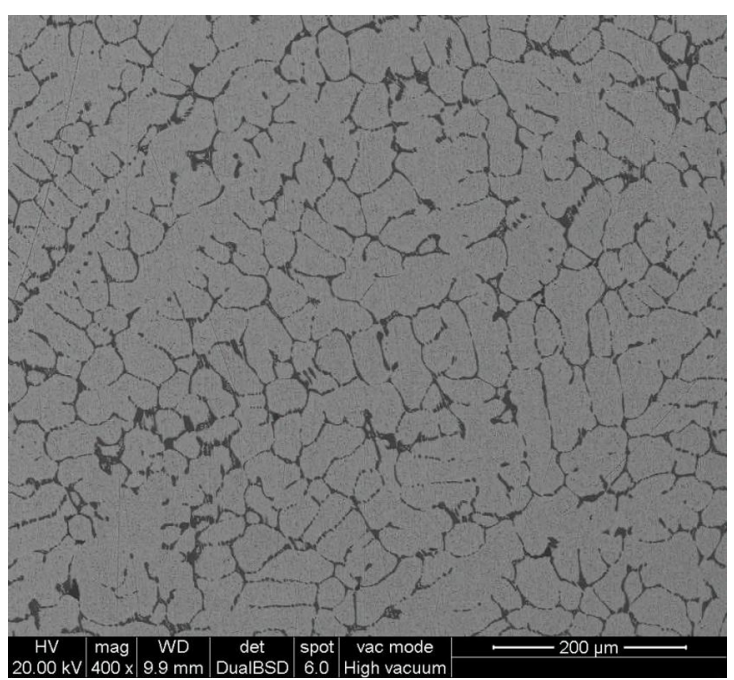

Figura 1. Microstructure of the $\mathrm{CuNiSiCr}$ alloy at as cast condition

The ingot, immediately after casting, has a fine grain structure (approximately $40 \mu \mathrm{m} \pm 10$ ), with an extensive second phase in most of the limits. One of the problems that second phases distribution entails is that of making the material difficult to form when its condition is fragile; an assertion that is true in most cases. As this is an alloy with thermally treatable characteristics, it is necessary to solubilize it at high temperatures in the first part of the manufacturing process, then, to temper it in water and finally, to induce the precipitation of particles coherent with the matrix. With this 
treatment the necessary hardening is achieved for the service. However, catastrophic breaks occur when the sample is tempered in water. When observing the fracture surfaces by microscopy; it is possible to verify this behavior is associated to a fragile structure in grain border. In Figures 2 and 3 the type of breakage can be observed: fragile, intergranular type and following the path of the second phases in the limit.

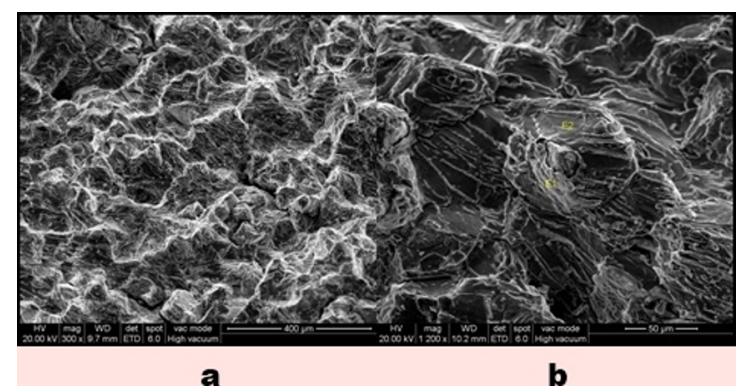

Figure 2. (a) CuNiSiCr alloy fracture surface after quenching, (b) EDAX analysis at two points (E1 and E2) of the segregated phase.

The EDS analyzes of the exposed phases on the fracture surfaces are shown in the following Table 1. In addition to being continuous and susceptible to the temperature of the solution treatment, second phases introduce silicon, nickel and chromium as constituent elements of the secreted phase. Obviously, a solubilization temperature as high as $1000^{\circ} \mathrm{C}$ promotes the increase of brittleness in this phase and subsequent break in the cooling.

\subsection{Characterization of the annealed stage}

In the following sequence of micrographs, the resulting structure of the homogenization heat treatment of an ingot of the CuNiSiCr alloy, Figure 3, also called annealing (b), is compared to the casting structure Figure 3 (a). This treatment is performed at $950^{\circ} \mathrm{C}$ for 7.5 hours and then the samples are quenched in water at room temperature. No effect regarding the reduction of segregation is observed in the micrographs; evidently, this treatment should not be part of the manufacturing process as it does not generate a smaller amount of precipitate.
Table 1. resulting elements found in the segregated phase

\begin{tabular}{ccccc}
\hline \multicolumn{5}{c}{ Elements found in the analysis by EDAX } \\
\hline $\begin{array}{c}\text { Examined } \\
\text { area }\end{array}$ & Silicón & Nickel & Chrome & Copper \\
\hline E1 & $\checkmark$ & $\checkmark$ & $\checkmark$ & resto \\
E2 & Traces & Traces & Traces & Mostly \\
\hline
\end{tabular}

Regarding morphology, type and quantity of second phases, the sequence of expansions of the microstructure shown in Figures 3 (c) and (d) enables to clearly locate and distinguish the shape of these phases. The EDAX analysis of gray areas (marked with the letter A, in red), confirms that these are nickel silicides and are located bordering the copper grains. Precipitation of another phase of black color (B), which turns out to be a chromium silicide is also observed in this phase. According to the literature, these two phases precipitate simultaneously in the last liquid that solidifies. However, they are also found inside the grains, forming as discontinuous precipitation. These phases are also indicated in Figure 3 (a) that is a casting structure.

\subsection{Characterization of forging stage}

The first attempts to forge the CuNiSiCr alloy in the homogenized condition are difficult because the material cracks in some of the stages of the forging process and a plate thickness of $12 \mathrm{~mm}$ cannot be reached. The cracks observed are fragile and very frequent; this means that it is necessary to generate another type and distribution of precipitates in the microstructure. The total annealing is one of the paths chosen to generate a different microstructure and increase the workability of the material.

Next, in Figure 4, the micrographs of the material with a total anneal at $950{ }^{\circ} \mathrm{C}$ for 7.5 hours and then oven-cooled for 24 hours at room temperature are shown.

The comparison between micrographs (a) and (c) suggests that there is an increase in the amount of precipitate within the grains. The morphology of these can be seen in micrograph (b) of Figure 4, in a yellow circle. These precipitates present polygonal contours when they grow in excess. In addition, precipitates of chromium silicide (black phases) attached

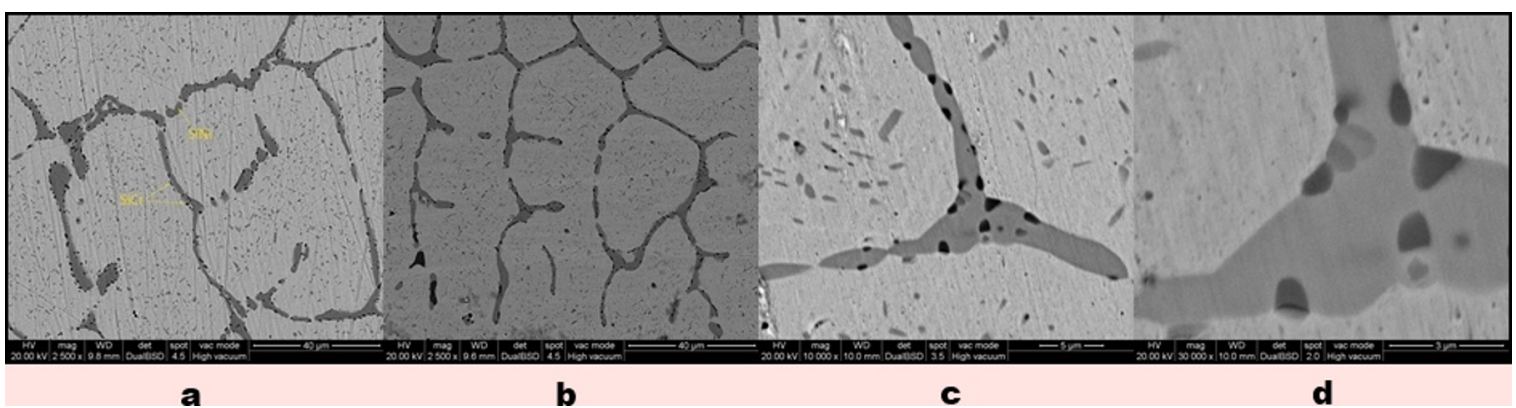

Figure 3. CuNiSiCr alloy. (A) as cast condition. (B) Annealed at $900{ }^{\circ} \mathrm{C}$ for 7.5 hours and quenched. (C) and (d) zoom of the region with second phases. 


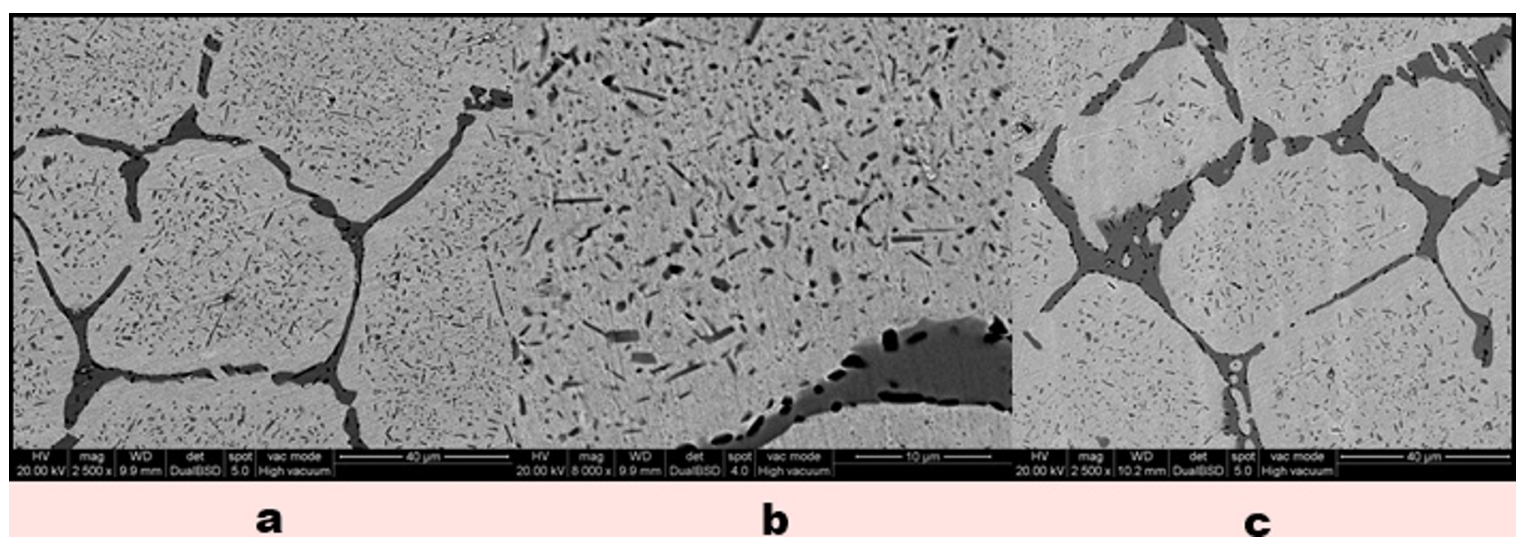

Figure 4. CuNiSiCr Alloy annealed at $950{ }^{\circ} \mathrm{C}$ for 7.5 hours (a) oven-cooled for $24 \mathrm{~h}$, (b) zoom of the above micrograph and (c) quenched.

to the silicides of nickel, similar to the events occurring at the grain boundaries are observed. The adjacencies of the grains are free from precipitation.

To verify the workability of this type of microstructure, several specimens are submitted to the free forging process. The initial results show a microstructure where the continuity of the segregated structure has been broken, as shown in Figure 5 (a). The size of the precipitates, both the chromium silicide and the nickel inside (the grains), has not changed much regarding the unshaped microstructures (always less than $2 \mu \mathrm{m})$. However, the continuity of the nickel silicide phase in grain boundary has been broken, remaining in the form of "islands" of precipitates scattered by the matrix. Obviously, this phase distribution is much more favorable in terms of strength and toughness.

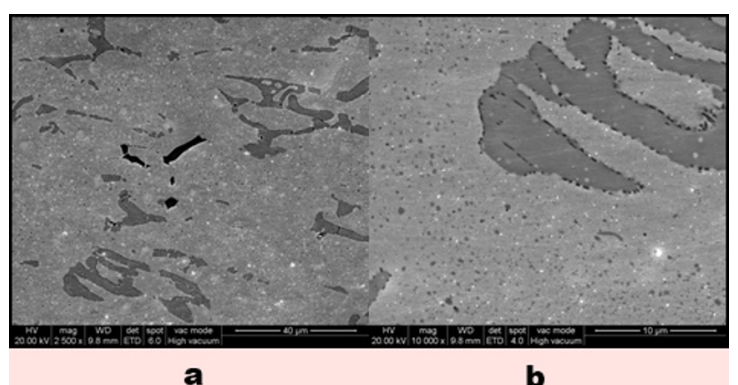

Figure 5. CuNiSiCr alloy annealed at $900{ }^{\circ} \mathrm{C}$ for 7.5 hours ovencooled and forged (a) overview, (b) zoom of the precipitate array.

\section{Conclusions}

The microstructure observed in Figure 5 (b), is the result of the formation of the $\mathrm{CuNiSiCr}$ alloy by forging at controlled temperatures between 790 and $950{ }^{\circ} \mathrm{C}$. The material is pretreated thermally by total annealing. Total destruction of the casting structure, which is not achieved with homogenization treatments, even in times of more than 10 hours and at temperatures of more than $900^{\circ} \mathrm{C}$ can be observed.
After forging, the sample is aged at temperatures of $510{ }^{\circ} \mathrm{C}$. The hardness achieved after all these treatments is greater than $32 \mathrm{HRc}$ with a conductivity of more than $27 \%$ IACS. These characteristics are similar to those presented by $\mathrm{CuBe}$ alloys, being then an alloy of possible replacement.

Finally, the preliminary tests carried out so far indicate that the properties of the $\mathrm{CuNiSiCr}$ forged alloy make it a suitable material for a wide variety of applications, especially those requiring a good combination of high thermal conductivity, corrosion resistance and good surface finish.

\section{Acknowledgments}

The authors thank the Manager of the company Coopersol SA, Mr. F.Marchiori, for providing the material used in this work.

\section{References}

1. Corson MG, inventor; Electro Metallurg Co., assignee. Copper alloy and process of producing and treating the same. United States patent US 1658186. 1928 Fev 7.

2. Edens WW, Ingerson QF, inventors; Ampco-Pittsburgh Corporation, assignee. Copper-nickel-silicon-chromium alloy having improved electrical conductivity. United States patent US 4191601. 1980 Mar 4.

3. Maffia EG, Tovio D, Moscoso CV, González A. Efecto del Tratamiento de Homogeneización en la Trabajabilidad en CuNiSiCr. In: V Congreso Bolivariano de Ingeniería Mecánica/ II Congreso Binacional de Ingeniería Mecánica; 2008 Jun 16-20; Cúcuta, Colombia.

4. Rdzawski Z, Stobrawa J. Thermomechanical processing of $\mathrm{Cu}-\mathrm{Ni}-\mathrm{Si}-\mathrm{Cr}-\mathrm{Mg}$ alloy. Materials Science and Technology. 1993;9(2):142-150.

5. Caron RN, Barth RG, Tyler DE, Brass O. Metallography and Microstructures of Copper and Its Alloys, Metallography and Microstructures. In: ASM Handbook Volume 9, Metallography and Microstructures. Materials Park: ASM International; 2004. p. $775-788$. 